九州大学学術情報リポジトリ

Kyushu University Institutional Repository

\title{
An Application of Growth Analysis Method to Simple Correlation Analysis between Dry Matter Indigestibility and Lignin Content with Growth of a Forage
}

Shimojo, Masataka

Laboratory of Animal Feed Science, Faculty of Agriculture, Kyushu University

Bungo, Takashi

Laboratory of Animal Feed Science, Faculty of Agriculture, Kyushu University

Tobisa, Manabu

Laboratory of Animal Feed Science, Faculty of Agriculture, Kyushu University

Imura, Yoshimi

Laboratory of Animal Feed Science, Faculty of Agriculture, Kyushu University

他

https://doi.org/10.5109/24259

出版情報：九州大学大学院農学研究院紀要. 43 (1/2)，pp.127-136，1998-11. Kyushu University バージョン：

権利関係 : 


\title{
An Application of Growth Analysis Method to Simple Correlation Analysis between Dry Matter Indigestibility and Lignin Content with Growth of a Forage
}

\author{
Masataka Shimojo, Takashi Bungo, Manabu Tobisa, Yoshimi Imura, \\ Naoki Koga, Shao Tao, Muhammad Yunus, Yutaka Nakano*, \\ Ichiro Goto, Mitsuhiro Furuse and Yasuhisa Masuda
}

\author{
Laboratory of Animal Feed Science, Faculty of Agriculture, \\ Kyushu University, Fukuoka 812-8581, Japan \\ (Received July 31, 1998 and accepled August 7, 1998)
}

\begin{abstract}
This study was conducted to apply the growth analysis method to the simple correlation analysis between dry matter indigestibility [DMI] and lignin content [LC] with growth of a forage. The growth was set between each sampling day $\left[t_{3}\right]$ and the day $\left[t_{m}\right]$, estimated from the regression line, when the mean value was given for each of DMI and LC. Terms used in the growth analysis method were forage relative growth rate [RGRw], the formation rate of indigestible materials for measured data [FRI] and that for estimated data [fri] from the regression line between DMI and LC, the formation rate of lignin [FRL], and the formation of indigestible materials per unit increase in lignin for measured data [FlL] and that for estimated data [fil]. The following results were obtained: The correlation coefficient [r], regression coefficient $[b]$ and standard error of estimates [SEE] in the simple correlation analysis between DMI and LC were described using RGRw, FRl, fri, FRL, FIL and fil. FIL, fil, and the ratio or the difference between them seemed to influence, in some degrec, the determination of $r, b$ or SEE. It was suggested that the simple correlation analysis between IPMI and IC was described using growth analysis method, implying influences of FIL and fil on the determination of $r, b$ and SEE.
\end{abstract}

\section{INTRODUCTION}

There is a positive correlation between dry matter indigestibility [DMI] and lignin content [LC] in the growth of a forage, and this is a reverse expression of the negative correlation of dry matter digestibility [DMD] with LC (Van Soest, 1982; Minson, 1990).

In the simple correlation analysis between two items, differences between each observed value and the mean value of observed values in each item are used to evaluate the correlation (Snedecor and Cochran, 1967a, b). It seems in the case of DMI and LC that above differences are those occurring in the period between each sampling day and the day when the mean value is given for each of DMI and LC. We showed that the increase in DMI with growth of forages was described using forage relative growth rate and formation rates of lignin and indigestible materials (Shimojo et al., 1995, 1997a, b, $1998 \mathrm{a}, \mathrm{b})$. These suggest, therefore, a possibility of an application of this growth analysis method to the simple correlation analysis between DMI and LC in the growth of a forage, provided that the day when the mean value is given for each of DMI, LC and their components is estimated.

\footnotetext{
* Kyushu University Farm, Éukuoka 811-2307
} 
The present study was designed to suggest a procedure for the expression of the simple correlation analysis between DMI and LC with growth of a forage, using the method of growth analysis between each sampling day and the day when the mean value is given for each of DMI and LC, and followed by an application to three tropical grasses.

\section{ESTIMATING THE DAY WHEN MEAN VALUE IS GIVEN FOR EACH OF DMI AND LC IN THE SIMPLE CORRELATION ANALYSIS BETWEEN THEM}

The DMI and LC measured for samples collected at time $t_{k}(k=1,2, \ldots, n)$ in the growth of a forage are expressed as $Y_{k}$ and $X_{k}$, respectively. The dry matter indigestibility estimated from the regression line between $Y_{k}$ and $X_{k}$ is expressed as $y_{k}$ [dmi]. Then, the mean dmi (=mean DMI) and the mean LC that is common to the measured values and the estimated values are expressed as $y_{m}\left(=Y_{m}\right)$ and $X_{m}$, respectively.

Using $X_{m}$ and $y_{m}$ on the regression line, the following equality is suggested when $\left(X_{m}, y_{m}\right)$ is found between $\left(X_{k}, y_{k}\right)$ and $\left(X_{k+1}, y_{k+1}\right)$,

$$
\frac{X_{m}-X_{k}}{X_{k+1}-X_{k}}=\frac{y_{m}-y_{k}}{y_{k+1}-y_{k}} \text {. }
$$

In the present study, the time $\left[t_{n}\right]$ when the mean value is given for each of $y_{n}$ and $X_{m}$ might be estimated as follows:

$$
t_{m}=t_{k}+\frac{X_{m}-X_{k}}{X_{k+1}-X_{k}} \cdot\left(t_{k+1}-t_{k}\right), \quad \text { or } \quad t_{m_{k}}=t_{k}+\frac{y_{m}-y_{k}}{y_{k+1}-y_{k}} \cdot\left(t_{k+1}-t_{k}\right) .
$$

Then, $\left(X_{k}, Y_{k}\right),\left(X_{k}, y_{k}\right)$ and $\left(X_{m}, y_{m}\right)$ are described as follows, respectively:

$$
\begin{aligned}
& \left(X_{k}, Y_{k}\right)=\left(\frac{L_{k}}{W_{k}}, \frac{I_{k}}{W_{k}}\right), \\
& \left(X_{k}, y_{k}\right)=\left(\frac{L_{k}}{W_{k}}, \frac{i_{k}}{W_{k}}\right), \\
& \left(X_{m}, y_{m}\right)=\left(\frac{L_{m}}{W_{m}}, \frac{i_{m}}{W_{m}}\right),
\end{aligned}
$$

where $W_{k}=$ measured dry weight of forage at $t_{k}, L_{k}=$ measured amount of lignin at $t_{k}$, $I_{k}=$ measured dry weight of indigestible materials at $t_{k}, i_{k}=$ estimated dry weight of indigestible materials at $t_{k}$ using the regression line, $W_{m}$ =estmated forage dry weight at $t_{m}$ $\left\{\neq\left(\sum W_{k}\right) / n\right\}, L_{m}=$ estimated amount of lignin at $t_{m}\left\{\neq\left(\sum L_{k}\right) / n\right\}, i_{m}=$ estimated dry weight of indigestible materials at $t_{n}\left\{\neq\left(\sum i_{k}\right) / n\right\}$.

$W_{m}, L_{m}$ and $i_{m}$ are considered difficult to estimate, but in the present study they are each estimated according to the following procedures. As $\left(X_{m}, y_{m}, t_{m}\right)$ is set between $\left(X_{k}\right.$, $\left.y_{k}, t_{k}\right)$ and $\left(X_{k-1}, y_{k+1}, t_{k+1}\right)$ on the regression line, $W_{m}$ that is common to dmi, DMI and LC might be estimated as follows:

$$
W_{m}=W_{k}+\frac{t_{m}-t_{k}}{t_{k+1}-t_{k}} \cdot\left(W_{k+1}-W_{k}\right)
$$


Then, $L_{m}$ and $i_{m}$ might be estimated as follows, respectively:

$L_{m}=W_{m} \cdot X_{m}$,
$i_{m}=W_{m} \cdot y_{m}$

As $y_{m}=Y_{m}$ and $W_{m i}$ is common to $y_{m}$ and $Y_{m}, i_{m}=I_{m}$. Thus,

$$
\left(X_{m}, Y_{m}\right)=\left(\frac{L_{m}}{W_{m}}, \frac{I_{m}}{W_{m}}\right) \text {, }
$$

where $I_{m}=$ estimated dry weight of indigestible materials at $l_{m}\left\{\neq\left(\sum I_{k}\right) / n\right\}$.

The following is also obtained,

$$
I_{m}=W_{m} \cdot Y_{m} \text {. }
$$

We believe that there are other reliable methods of estimating $l_{m}, W_{m}, L_{m}, \dot{z}_{m}$ and $I_{m}$, but unfortunately we do not know them for the present. The use of equations (1) (10) should be limited to the cases where there are normal relationships between DMI and LC, otherwise there will occur the difficulty in estimating $t_{m}$ due to the large dispersion of data causing low coefficients of correlation.

Tables 1,2 and 3 show an application of equations (1) (10) to three tropical grasses, namely Rhodes grass [Rg] (Chloris gayana Kunth), dallis grass [Dg] (Paspalum dilatatum Poir.) and bermuda grass $[\mathrm{Bg}]$ (Cynodon dactylon (L.) Pers.), which were regrown at our experimental field with a dressing of a compound fertilizer ( $\mathrm{N}: \mathrm{P}_{2} \mathrm{O}_{5}: \mathrm{K}_{2} \mathrm{O}=14: 14: 14 \%$ ), after the first cut and discard, at a rate of $1.0 \mathrm{~kg} / \mathrm{a}$ in $\mathrm{Rg}$ and $0.7 \mathrm{~kg} / \mathrm{a}$ in Dg and Bg for each element. In these cases, $t_{n}, W_{m}, L_{m}, i_{n n}$ and $I_{n}$ were estimated for each grass using corresponding regression line.

In the present study, $\left(X_{m} / W_{m}, i_{m} / W_{m}, t_{m}\right)$ and $\left(X_{m} / W_{m}, I_{m} / W_{m}, t_{m}\right)$ will be used as a set of mean values for the estimated values $\left(X_{k} / W_{k}, i_{k} / W_{k}, t_{k}\right)$ and the measured values $\left(X_{k} / W_{k}\right.$, $\left.I_{k} / W_{k}, t_{k}\right)$, respectively, in the application of growth analysis method to the simple correlation analysis between DMI and LC with growth of a forage.

Table 1. Characteristies of Rhodes grass [Rg] and estimation of $\ell_{w}$ when mean dry matter indigestibility

\begin{tabular}{|c|c|c|c|c|}
\hline$t_{\Lambda}$ (days) & 25 & 41 & 74 & $37.19\left(t_{m}\right)$ \\
\hline$W_{l}\left(\mathrm{~g} / \mathrm{m}^{-}\right)$ & 223.85 & 398.98 & 593.32 & $357.24\left(W_{m}\right)$ \\
\hline$L_{k}\left(\mathrm{~g} / \mathrm{m}^{\prime}\right)$ & 8.81 & 29.36 & 49.45 & $23.37\left(L_{m a}\right)$ \\
\hline$I_{k}\left(\mathrm{~g} / \mathrm{m}^{2}\right)$ & 67.87 & 190.55 & 326.49 & $158.50\left(I_{m}\right)$ \\
\hline$i_{\hbar}(\mathrm{g} / \mathrm{m})$ & 67.33 & 194.86 & 321.50 & $158.50\left(i_{m}\right)$ \\
\hline$X_{k}\left(=L_{k} / W_{k}\right)$ & 0.0394 & 0.0736 & 0.0833 & $0.0654\left(X_{i \prime \prime}\right)$ \\
\hline$Y_{:}\left(=I, / W_{i}\right)$ & 0.3032 & 0.4776 & 0.5503 & $0.4437\left(Y_{* i n}\right)$ \\
\hline$y_{i}\left(=i / W_{i}\right)$ & 0.3008 & 0.4884 & 0.5419 & $0.4437\left(y_{1}\right)$ \\
\hline
\end{tabular}
[DMI], lignin content [LC] and their components are given.

$t_{i}=$ regrowth days, $W_{k}=$ rneasured dry weight of forage, $L_{\mathrm{k}}=$ measured amount of lignin, $I_{k}=$ measured dry weight of indigestible materials, $i_{k}=$ estimated dry weight of indigestible materials using the regression line, $X_{s}=$ measured lignin content [LC], $Y_{t}=$ measured dry matter indigestibility [D)MI], $y_{k}=$ estimated dry matter indigestibility [dmi] using the regression line, $X_{m}=$ mean LC, $Y_{m}=$ Inean DMI, $i_{m}=$ mean dmi, $t_{m}=$ the day when $X_{n}$ and $y_{m}\left(=Y_{m}\right)$ are given, $W_{m}=W$ at $t_{m}, L_{m}=W_{m} \cdot X_{m}, I_{m}=W_{m} \cdot Y_{m,}, i_{m}=W_{m} \cdot y_{m}$. 
Table 2. Characteristics of dallis grass [Dg] and estimation of $t_{: i}$ when mean dry matter indigestibility [DMI], lignin content [LC] and their components are given.

\begin{tabular}{|c|c|c|c|c|}
\hline$t_{*}$ (days) & 20 & 59 & 80 & $60.87\left(t_{1: i}\right)$ \\
\hline$W_{k}\left(g / m^{\prime}\right)$ & 213.20 & 676.53 & 780.40 & $685.78\left(W_{m}\right)$ \\
\hline$L_{k}\left(\mathrm{~g} / \mathrm{m}^{-}\right)$ & 6.20 & 28.35 & 46.36 & $29.81\left(I_{m i}\right)$ \\
\hline$I_{:}\left(\mathrm{g} / \mathrm{m}^{2}\right)$ & 59.16 & 272.10 & 422.90 & $279.25\left(I_{\mathrm{m}}\right)$ \\
\hline$i_{k}\left(\mathrm{~g} / \mathrm{m}^{2}\right)$ & 60.21 & 266.33 & 425.71 & $279.25\left(i_{i 1}\right)$ \\
\hline$X_{k}\left(=L_{n} / W_{k}\right)$ & 0.0291 & 0.0419 & 0.0594 & $0.0435\left(X_{m}\right)$ \\
\hline$Y_{i}\left(=I ; / W_{k}\right)$ & 0.2775 & 0.4022 & 0.5419 & $0.4072\left(Y_{m}\right)$ \\
\hline$y_{k}\left(=i_{k} / W_{k}\right)$ & 0.2824 & 0.39337 & 0.5455 & $0.4072\left(y_{m}\right)$ \\
\hline
\end{tabular}

The explanation of symbols and terms are stiown in the footnote of Table 1.

Table 3. Characteristics of bermuda grass $[\mathrm{Bg}]$ and estimation of $t_{m}$ when mean dry matter indigestibility [DMI], lignin content [LC] and their components are given.

\begin{tabular}{|c|c|c|c|c|}
\hline$t_{k}$ (days) & 20 & 59 & 80 & $50.68\left(t_{r u}\right)$ \\
\hline$W_{k}\left(\mathrm{~g} / \mathrm{m}^{2}\right)$ & 203.40 & 424.80 & 767.20 & $377.57\left(W_{n}\right)$ \\
\hline$L_{*}\left(\mathrm{~g} / \mathrm{m}^{2}\right)$ & 5.45 & 19.16 & 39.66 & $15.55\left(L_{\text {(t) }}\right)$ \\
\hline$I_{\text {i. }}\left(\mathrm{g} / \mathrm{m}^{2}\right)$ & 76.44 & 211.85 & 389.89 & $174.02\left(I_{i i i}\right)$ \\
\hline$i_{k}\left(g / \mathrm{m}^{2}\right)$ & 77.29 & 205.11 & 398.84 & $174.02\left(i_{m}\right)$ \\
\hline$X_{k}\left(=L_{k} / W_{i}\right)$ & 0.0268 & 0.0451 & 0.0517 & $0.0412\left(X_{m}\right)$ \\
\hline$Y_{k}\left(=I_{h} / W_{i}\right)$ & 0.3758 & 0.4987 & 0.5082 & $0.4609\left(Y_{m}\right)$ \\
\hline$y_{i}\left(=i_{i} / W_{k}\right)$ & 0.3800 & 0.4828 & 0.5199 & $0.4609\left(y_{m}\right)$ \\
\hline
\end{tabular}

The explanation of symbols and terms are shown in the footnote of Table 1.

\section{DESCRIPTION OF CHANGES IN dmi, DMI AND LC BETWEEN $t_{k}$ and $t_{m}$}

The changes in dmi and those in DMI between $t_{k}$ and $t_{m}$ are described on referring to our previous reports (Shimojo et al., 1995, 1997a, b, 1998a, b). For the convenience of calculation, changes in dmi (estimated) are described as follows:

Changes in $\mathrm{dmi}=y_{k}-y_{m}$

$$
\begin{aligned}
& =\frac{i_{k}}{W_{k}}-\frac{i_{m}}{W_{m}} \\
& =\left(1-\frac{W_{m}}{W_{k}}\right) \cdot\left(\frac{\overline{\text { fri }}}{\text { RGR }_{\mathrm{w}}}-\frac{i_{m}}{W_{m}}\right),
\end{aligned}
$$

where fri=formation rate of estimated indigestible materials per unit $W[(1 / W) \cdot(d i / d t)]$, $\mathrm{RGR}_{\mathrm{w}}=$ relative growth rate of forages $[(1 / W) \cdot(d W / d t)]$.

$\overline{\text { fri and }} \overline{\mathrm{RGR}_{w}}$ are approximated as follows: 
$\overline{\text { fri }}=\frac{\log _{e} W_{k}-\log _{e} W_{m}}{W_{k}-W_{m}} \cdot \frac{i_{k}-i_{m}}{t_{k}-t_{m}}$,

$\overline{\mathrm{RGR}_{\mathrm{w}}}=-\frac{\log _{e} W_{k}-\log _{e} W_{m}}{t_{k}-t_{m}}$,

where $e=$ the base of natural logarithm.

Therl, changes in DMI (measured) is expressed as follows:

Changes in DMI $=Y_{k}-Y_{m}$

$$
\begin{aligned}
& =\frac{I_{k}}{W_{k}}-\frac{I_{m}}{W_{m}} \\
& =\left(1-\frac{W_{m}}{W_{k}}\right) \cdot\left(\frac{\overline{\mathrm{FRI}}}{\overline{\mathrm{RGR}_{\mathrm{w}}}}-\frac{I_{m}}{W_{m}}\right),
\end{aligned}
$$

where $\mathrm{FRI}=$ formation rate of measured indigestible materials per unit $W[(1 / W) \cdot(d I / d t)]$.

$\overline{\mathrm{FRI}}$ is approximated as follows:

$$
\overline{\mathrm{FRI}}=\frac{\log _{e} W_{k}-\log _{e} W_{m}}{W_{k}-W_{m}} \cdot \frac{I_{k}-I_{m}}{t_{k}-t_{m}} .
$$

The comparison of equations (11) and (14) suggests that the difference between dmi changes and DMI changes is due to the difference between fri and FRI. Both fri and FRI are divided furthermore into two components as follows, respectively:

$$
\begin{aligned}
& \text { fri }=\frac{1}{W} \cdot \frac{d i}{d t}=\left(\frac{1}{W} \cdot \frac{d L}{d t}\right) \cdot \frac{d i}{d L}, \\
& \mathrm{FRI}=\frac{1}{W} \cdot \frac{d I}{d t}=\left(\frac{1}{W} \cdot \frac{d L}{d t}\right) \cdot \frac{d I}{d L},
\end{aligned}
$$

where $(1 / W) \cdot(d L / d t)=$ formation rate of lignin $[L]$ per unit $W[\mathrm{FRL}], d i / d L=$ formation of $i$ per unit increase in $L$ [fil], $d I / d L=$ formation of $I$ per unit increase in $L$ [FL].

Therefore, fil and FIL might make the difference between changes in dmi and those in DMI through the difference between fri and FRI. Fil and $\overline{\text { FIL }}$ are approximated as follows:

$$
\overline{\mathrm{fil}}=\frac{i_{k}-i_{m}}{L_{k}-L_{m}}, \quad \overline{\mathrm{FI}}=\frac{I_{k}-i_{m}}{L_{k}} . L_{m} .
$$

Likewise, changes in LC is described as follows:

Changes in $\mathrm{LC}=X_{k}-X_{m}$

$$
\begin{aligned}
& =\frac{L_{k}}{W_{k}}-\frac{L_{m}}{W_{m}} \\
& =\left(1-\frac{W_{m}}{W_{k}}\right) \cdot\left(\frac{\overline{\overline{F R L}^{2}}}{\overline{R G R}_{w}}-\frac{L_{m}}{W_{m}}\right) .
\end{aligned}
$$


$\overline{\text { FRL }}$ is approximated as follows:

$$
\overline{\mathrm{FRL}}=\frac{\log _{e} W_{k}-\log _{e} W_{m}}{W_{k}-W_{m}} \cdot \frac{L_{k}-L_{m}}{t_{k}-t_{m}} .
$$

\section{APPLICATION OF EQUATIONS (11), (14) AND (19) TO SIMPLE CORRELATION ANALYSIS BETWEEN DMI AND LC}

In the simple correlation analysis between two items, correlation coefficient, regression coefficient and standard error of estimates are determined at least to give a broad outline of the correlation (Snedecor and Cochran, 1967a, b).

\section{(A) Correlation coefficient}

For pairs of $\left(X_{k}, Y_{k}\right)$, correlation coefficient $[\mathrm{r}]$ is described as follows:

$$
\mathrm{r}=\frac{\sqrt{\sum_{k=1}^{n}\left(y_{k}-y_{m}\right)^{2}}}{\sqrt{\sum_{k=1}^{n}\left(Y_{k}-Y_{m}\right)^{2}}} .
$$

An application of equations (11) and (14) to the calculation of $r$ gives

$$
\begin{aligned}
\mathbf{r} & =\frac{\sqrt{\sum_{k=1}^{n}\left\{\left(1-\frac{W_{m}}{W_{k}}\right) \cdot\left(\frac{\overline{\text { fri }}}{\overline{\mathrm{RGR}_{\mathrm{w}}}}-\frac{i_{m}}{W_{m}}\right)\right\}^{2}}}{\sqrt{\sum_{k=1}^{n}\left\{\left(1-\frac{W_{m}}{W_{k}}\right) \cdot\left(\frac{\overline{\mathrm{FRI}}}{\overline{\mathrm{RGR}_{\mathrm{w}}}}-\frac{I_{m}}{W_{m}}\right)\right\}^{2}}} \\
& =\frac{\sqrt{\sum_{k=1}^{n}\left\{\left(1-\frac{W_{m}}{W_{k}}\right) \cdot\left(\overline{\overline{\mathrm{FRL}} \cdot \overline{\mathrm{fil}}}-\frac{i_{m}}{\mathrm{RGR}_{\mathrm{w}}}\right)\right\}_{m}^{2}}}{\sqrt{\sum_{k=1}^{n}\left\{\left(1-\frac{W_{m}}{W_{k}}\right) \cdot\left(\frac{\overline{\mathrm{FRL} \cdot \overline{\mathrm{FIL}}}}{\overline{\mathrm{RGR}}}-\frac{I_{m}}{W_{m}}\right)\right\}^{2}}} .
\end{aligned}
$$

Equation (22) suggests that as $i_{n}=I_{m}$, the determination of $\mathrm{r}$ is influenced by the relationship between fil and FIL, roughly speaking, the ratio of fil to FIL.

\section{(B) Regression coefficient}

The regression line for $\left(X_{k}, Y_{k}\right)$ is expressed as $Y=\mathrm{a}+\mathrm{b} X$ where $\mathrm{b}$ is the regression coefficient. Thus, $\mathrm{b}$ is described as follows:

$\mathrm{b}=\frac{\sqrt{\sum_{k=1}^{n}\left(y_{k}-y_{m}\right)^{2}}}{\sqrt{\sum_{k=1}^{n}\left(X_{k}-X_{m}\right)^{2}}}$.

An application of equations (11) and (19) to the calculation of $b$ gives 


$$
\begin{aligned}
& \mathrm{b}=\frac{\sqrt{\sum_{k=1}^{n}\left\{\left(1-\frac{W_{m}}{W_{k}}\right) \cdot\left(\frac{\overline{\text { fri }}}{\overline{\mathrm{RGR}_{\mathrm{w}}}}-\frac{i_{m}}{W_{m}}\right)\right\}^{2}}}{\sqrt{\sum_{k=1}^{n}\left\{\left(1-\frac{W_{m}}{W_{k}}\right) \cdot\left(\frac{\overline{\mathrm{FRL}}}{\overline{\mathrm{RGR}_{\mathrm{w}}}}-\frac{L_{m_{-}}}{W_{m}}\right)\right\}^{2}}}
\end{aligned}
$$

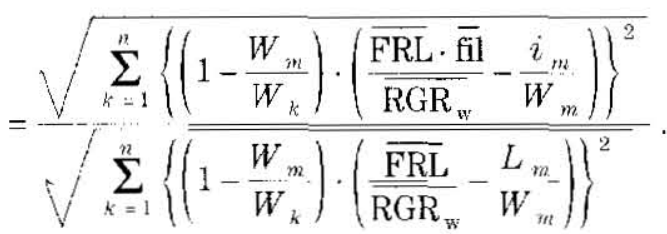

It is suggested in equation (24) that the determination of b is, roughly speaking, influenced by the presence of fil in the numerator and the ratio of $i_{m} / W_{m}$ to $L_{m} / W_{m}$.

\section{(C) Standard error of estimates}

Standard error of estimates [SEE] is related to the accuracy with which DMI is estimated from LC on the regression line. This sort of evaluation is of importance to the prediction of forage digestibility from chemical components in forages, and in Australian studics residual standard deviation is used (Minson, 1990).

SEE is described as follows:

$$
\begin{aligned}
\mathrm{SEE} & =\sqrt{\frac{\sum_{k=1}^{n}\left(Y_{k}-y_{k}\right)^{2}}{n-2}} \\
& =\sqrt{\frac{\sum_{k=1}^{n}\left\{\left(Y_{k}-Y_{m}\right)-\left(y_{k}-y_{m}\right)\right\}^{2}}{n-2}},
\end{aligned}
$$

where $Y_{m}=y_{m}$.

An application of equations (11) and (14) to the calculation of SEE gives

$$
\begin{aligned}
\mathrm{SEE} & =\sqrt{\frac{\sum_{k=1}^{n}\left\{\left(1-\frac{W_{m_{k}}}{W_{k}}\right) \cdot\left(\frac{\overline{\mathrm{FRI}}}{\overline{\mathrm{RGR}}}-\frac{I_{m}}{W_{m}}\right)-\left(1-\frac{W_{m}}{W_{k}}\right) \cdot\left(\frac{\overline{\mathrm{fri}}}{\overline{\mathrm{RGR}}}-\frac{i}{W_{m}}\right)\right\}^{2}}{n-2}} \\
& =\sqrt{\frac{\sum_{k=1}^{n}\left\{\left(1-\frac{W_{m}}{W_{k}}\right) \cdot\left(\frac{\overline{\mathrm{FRI}}}{\mathrm{RGR}}-\frac{\overline{\mathrm{fri}}}{\overline{\mathrm{RGR}}}\right)\right\}^{2}}{n-2}} \\
& =\sqrt{\frac{\sum_{k=1}^{n}\left\{\left(1-\frac{W_{m}}{W_{k}}\right) \cdot\left(\frac{\overline{\mathrm{FRL}}}{\overline{\mathrm{RGR}}}\right) \cdot(\overline{\mathrm{FIL}}-\overline{\mathrm{fil}})\right\}^{2}}{n-2}},
\end{aligned}
$$

where $I_{i n} / W_{m}=i_{n} / W_{m}$. 
Table 4. An application of growth aralysis method to simple correlation analysis between dry matter indigestibility [DMI] and lignin content [LC] in the growth of Rhodes grass [Rg].

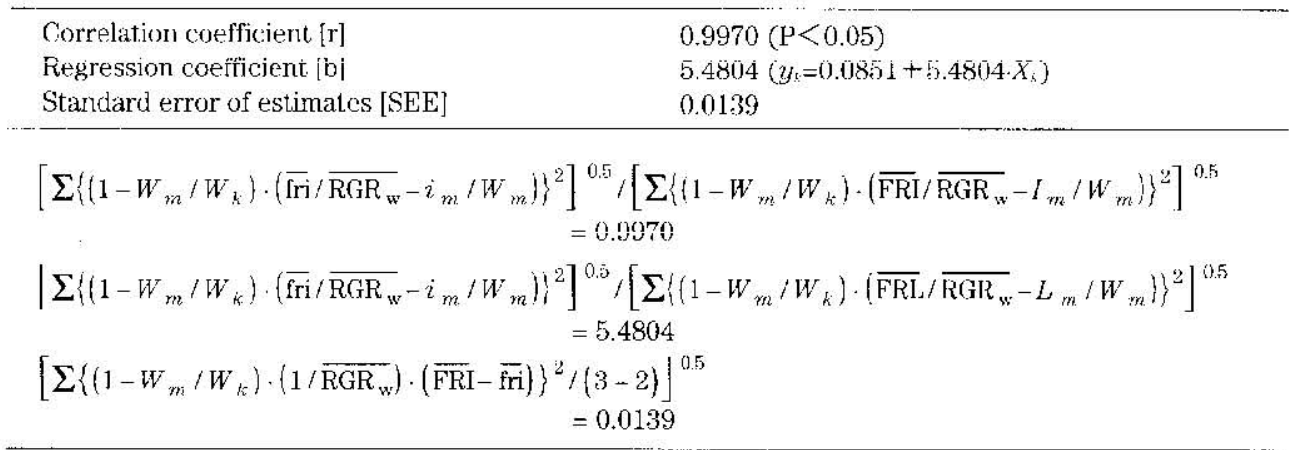

$W_{k}=$ measured dry weight of forage, $X_{i}=$ measured lignin content [LC], $Y_{k}=$ measured dry mattcr indigestibility [DMI], $y_{k}=$ estimated dry matter indigestibility [dmi] using the regression line, $X_{m}=$ mean LC, $Y_{m}=$ mean DMI, $i_{m}=$ mean dmi, $W_{m}=W$ at $t_{w}, L_{m}=W_{m} \cdot X_{m,}, I_{m}=W_{m} \cdot Y_{m}, i_{m}=W_{m} \cdot y_{m}, \overline{\text { fri }}=$ formation rate of estimated indigestible materials per unit $W, \overline{\mathrm{FRI}}=$ formation rate of measured indigestible materials per unit $W, \overline{\mathrm{FRL}}=$ formation rate of lignin per unit $W, \overline{\mathrm{RGR}}=$ forage relative growth ratc.

Table 5. An application of growth analysis method to simple correlation analysis belween dry matter indigestibility [DMMI] and lignin content [LC] in the growth of dallis grass [Dg].

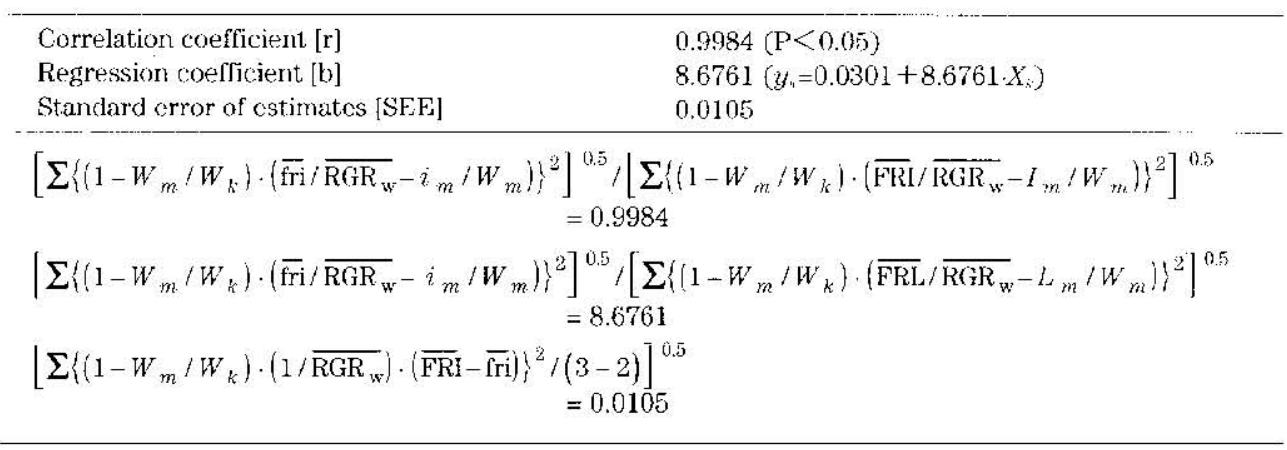

The explanation of symbols and terms are shown in the footnote of Table 4.

Equation (26) suggests that the determination of SEE is influenced by the relationship between FIL and fil, roughly speaking, the difference between them.

An application of equations (22), (24) and (26) to the calculation of $r$, b and SEE using actual data is shown for $\mathrm{Rg}$ (Table 4), $\mathrm{Dg}$ (Table 5) and $\mathrm{Bg}$ (Table 6). This suggests that the simple correlation analysis between DMI and LC is reduced, in some degree, to the relationships between FIL and fil, if growth analysis method is applied between each sampling day and the day when the mean value is given for each of DMI and LC. FIL and fil are considered indices for the relationship between lignification and the formation of 
indigestible materials with growth of forages in the measured data and in the estimated data, respectively. This might give a sort of growth analytic explanation of the simple correlation analysis between DMI and LC.

Table 6. An application of growth analysis method to simple correlation analysis between dry matter indigestibility [DMI] and lignin content. [LC] in the growth of bernuda grass [Bg].

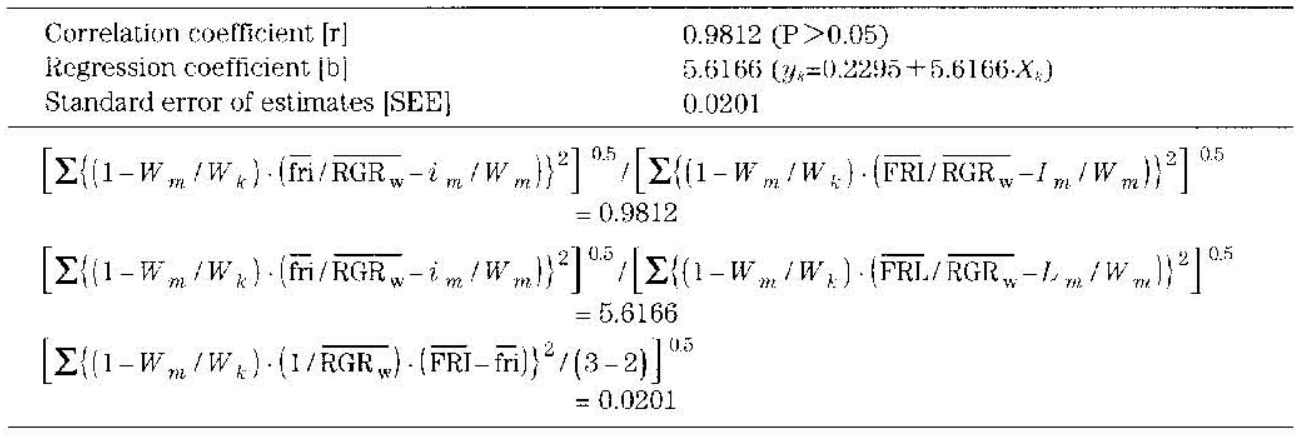

The explanation of symbols and terms are shown in the footnote of Table 4.

\section{Conclusions}

It is suggested from this study that the simple correlation analysis between DMI and LC with growth of a forage is described using RGRw, FRI, fri, FRL, FIL and fil which are calculated between each sampling day and the day when the mean value is given for each of DMI and LC. This implies, roughly speaking, influences of FIL and fil on the determination of $r$, $b$ and SEE.

\section{ACKNOWLEDGEMENTS}

The present study is based on our previous works on forage indigestibility and lignin content in which M̄r. Yasukatsu Yano showed his skilled technical assistance.

\section{REFERENCES}

Minson, D. J. 1990 Digestible energy of forage. In "Forage in Ruminant Nitrition", Academic Iress, fric., San Diego, pp. 85-149

Shimojo, M., Y. Masuda, T. Burigo, T. Kawamura and l. Goto 1995 Analytical expression for formation of indigestible materials and increase in dry matter indigestibility with growth of some tropical grasses. J. Fac. Agr., Kyushu linio., 40: 179-188

Stimojo, M., T. Bungo, Y. Tnima, Y. Tobisa, N. Koga, Y. Näkaño, I. Goto and Y. Masuda $1997 a$ Añ analysis of digestibility change with growh of forage. In "Present and future of numen research", Proc: First Joint Symp. Japan and Korea on Rumen Metab. Physiol., $\mathrm{P}-11$

Shimojo, M., Y. Imura, M. Tobisa, N. Koga, T. Bungo, Y. Nakano, T. Nishihira, I. Goto and Y. Masuda 1997b Formation of indigestible materials and increase in dry matter indigestibility in the growth of two tropical forages. J. Fac. Agr, Kyushu Vriw., 42: 95-99

Shimojo, M., Y. Inura, T. Bungo, M. Tobisa, N. Koga, S. Tao, M. Yunus, Z. Yin, Y. Nakano, I. Goto and Y. 
Masuda 1998a Formation of indigestible materials from digestible materials and photosynthates in the growth of Rhodes grass (Chioris gayana Kunth). J. Fac. Agr, Kyushu Uniz., 42: 355-360

Shimojo, M., T. Bungo, M. Tohisa, Y. Imura, N. Koga, S. Tao, M. Yunus, Y. Nakano, I. Goto, M. Furuse and Y. Masuda. 1998b Analyses of formation of indigestible materials and increase in dry matter indigestibility with growth of two tropical forages. Proc. Sth World Conf. Anim. Prod, Seoul, Korea, Vol. II: $508-509$

Snedecor, G. W. and W. G. Cochran I967a Regression. In "Statistical Methods", 6th ed. The Iowa State University Press, Ames, Iowa, pp. 135-171

Snedecor, G. W. and W. G. Cochran 1967b Correlation. In "Statistical Mothods", 6th ed. The Iowa State Iniviversity Press, Ames, Jowa, pp. 172-198

Van Soest, P. J. 1982 Nutritional quality. In "Nutritional Ecology of the Ruminant.", Cornell University Press, New York, pp. 23-74 